Original research article

\title{
Levels of polycyclic aromatic hydrocarbons in milk and milk powder samples and their likely risk assessment in Iranian population
}

\author{
Nabi Shariatifar ${ }^{\mathrm{a}, \mathrm{b}, \mathrm{c}}$, Manouchehr Dadgar ${ }^{\mathrm{b}}$, Yadolah Fakhri ${ }^{\mathrm{d}}$, Saeed Shahsavari ${ }^{\mathrm{e}}$, \\ Mojtaba Moazzen ${ }^{\mathrm{a}}$, Mahsa Ahmadloo ${ }^{\mathrm{f}}$, Amin $_{\mathrm{Kiani}}{ }^{\mathrm{g}}$, Saeed Aeenehvand ${ }^{\mathrm{h}}$, Shahrokh Nazmara ${ }^{\mathrm{a}, \mathrm{i}, *}$, \\ Amin Mousavi Khanegah, ${ }^{\mathrm{j}, * *}$
}

${ }^{a}$ Department of Environmental Health Engineering, School of Public Health, Tehran University of Medical Sciences, Tehran, Iran

${ }^{\mathrm{b}}$ Halal research center of IRI.FDA.MOH, Tehran, Iran

${ }^{\mathrm{c}}$ Food safety research center, Shahid Beheshti University of medical science, Tehran, Iran

${ }^{\mathrm{d}}$ Student Research Committee, School of Public Health and Safety, Shahid Beheshti University of Medical Sciences, Tehran, Iran

${ }^{\mathrm{e}}$ Health Products Safety Research Center, Qazvin University of Medical Sciences, Qazvin, Iran

${ }^{\mathrm{f}}$ Department of Food Safety and Hygiene, School of Public Health, Qazvin University of Medical Sciences, Qazvin, Iran

${ }^{\mathrm{g}}$ Department of Public Health, School of Public Health, Fasa University of Medical Sciences, Fasa, Iran

${ }^{\mathrm{h}}$ Department of Food Sciences and Technology/National Nutrition and Food Technology Research, Shahid Beheshti University of Medical Sciences, Tehran, Iran

${ }^{\mathrm{i}}$ Center for Water Quality Research (CWQR), Institute for Environmental Research (IER), Tehran University of Medical Sciences (TUMS), Tehran, Iran

${ }^{j}$ Department of Food Science, Faculty of Food Engineering, State University of Campinas (UNICAMP), Monteiro Lobato, 80. Caixa Postal: 6121. CEP, 13083-862,

Campinas, São Paulo, Brazil

\section{A R T I C L E I N F O}

\section{Keywords:}

Polycyclic aromatic hydrocarbons

Milk powdered

Pasteurized milk

Sterilized milk

Health risk assessment

Magnetic solid-phase extraction

GC-MS

Food analysis

Food composition

\begin{abstract}
A B S T R A C T
An MSPE/GC-MS method was used for the measuring of 16 PAHs and assessing of the effect of different factors on PAHs concentrations among different types of dairy products. Moreover, the probabilistic health risk assessment due to ingestion of PAHs by the consumption of milk and milk powder was evaluated. The limit of detection (LOD) and limit of quantitation LOQ were ranged between 0.040-0.075 and 0.121-0.227 $\mu$ g/ $\mathrm{kg}$, respectively. The highest mean of total PAHs was noted in milk powdered $(2.28 \pm 0.39 \mu \mathrm{g} / \mathrm{kg})$, while the lowest content was observed in pasteurized milk $(0.87 \pm 0.18 \mu \mathrm{g} / \mathrm{kg})$. Except for a few samples of milk powder, the PAHs contents of the other samples was lower than standard limits while the concentration of BaP was lower than of standard levels proposed by EU $(0.02-0.06 \mu \mathrm{g} / \mathrm{kg})$. Considering season effect, the samples in winter had the highest level of PAHs. The percentile 95\% actual THQ was the 3.64E-04 value that was lower than 1 value. Hence, the consumers are not at considerable non-carcinogenic health risk while the actual ILCR was 3.53E-03 as higher than 1E-04. Therefore, consumers are at considerable carcinogenic risk. Generally speaking, approaching the control plans for a decrease in the concentration of PAHs in dairy products in order to control carcinogenic health risk is crucial.
\end{abstract}

\section{Introduction}

Polycyclic aromatic hydrocarbons (PAHs) containing 2 or more fused aromatic rings are a common group of environmental contaminants with some adverse effects on human health (Ahmadkhaniha et al., 2014; Abdel-Shafy and Mansour, 2016). However, vehicular emissions may not be the only PAHs source; other probable sources include automobiles, refineries, power plants, asphalt particles, and stationary combustion sources or crematoria also play important roles in increasing the levels of this contaminant in the environment (Gorji et al., 2016; Ahmadloo et al., 2019). It is worth notable to state that PAHs could be produced over cooking procedures include roasting, grilling, smoking, drying and heating as the key proof for the incidence of PAHs in the human diet. Furthermore, food products can be polluted with PAHs via contaminated water, soil and air (Grova et al., 2002; Amiri et al., 2016). So far, the contamination by PAHs has been reported among diverse food products like vegetables, dairy products, meat products and etc. Amongst them, milk has been the subject of

\footnotetext{
* Corresponding author at: Department of Environmental Health Engineering, School of Public Health, Tehran University of Medical Sciences, Tehran, Iran.

** Corresponding author at: Department of Food Science, Faculty of Food Engineering, State University of Campinas (UNICAMP), Monteiro Lobato, 80. Caixa Postal: 6121. CEP, 13083-862, Campinas, São Paulo, Brazil.

E-mail addresses: snazmara@razi.tums.ac.ir (S. Nazmara), mousavi@unicamp.br (A. Mousavi Khanegah).
} 